\title{
LA MATERIA DE LA VOZ: UMBRALES Y FIGURAS
}

\author{
The matter of the voice: thresholds and figures
}

\author{
María Gabriela Milone \\ https://orcid.org/0000-0001-5342-3355 \\ Universidad Nacional de Córdoba, Instituto Nacional de Humanidades, \\ Córdoba, CB, Argentina. 5000 - idh@cordoba-conicet.gov.ar
}

Resumen: En el presente ensayo exponemos algunas líneas de reflexión contemporáneas sobre la voz, sus insistencias en la pregunta por el habla y su enlace con la cuestión de la voz como materia de la lengua. En este marco, una escena se repite: Babel, figura recuperada por diversos autores del pensamiento contemporáneo para reflexionar sobre la voz y su vinculación con la capacidad de hablar y donde la lengua se revitaliza en la vibración de su materia. Desde Giorgio Agamben, Roland Barthes, Jacques Derrida, Michel de Certeau, Daniel Heller-Roazen, Jean-Luc Nancy, entre otros, analizaremos la voz en el umbral del sonido, del sentido, de la letra, del habla, de la lengua. En estas reflexiones, la voz, como materia y como figura, expondrá su complejidad, su singularidad, su extensión, sus insistencias. De este modo, estas páginas se situarán en una zona liminal del pensamiento contemporáneo, donde algunas categorías se ven socavadas por la materia inclasificable de la voz.

Palabras-clave: Voz. Materia. Babel. Filosofía contemporánea.

Abstract: In this work we present contemporary ideas about the voice and its relationship with the language. We study the voice as a matter of language. We analyze the scene of Babel in contemporary thought: Giorgio Agamben, Roland Barthes, Jacques Derrida, Michel de Certeau, Daniel Heller-Roazen, Jean-Luc Nancy. From these theories, we will analyze the voice on the threshold of sound, of meaning, of letter, of speech, of language. This work is located in a limit zone of contemporary thought, where the classifications of the disciplines are questioned by the singular matter of the voice.

Keywords: Voice. Matter. Babel. Contemporary philosophy.

¿Qué voz hablará de la voz?

(J-L Nancy, 2007)

El lenguaje no es un instrumento para decir; es un utensilio de aparición: desgarra el mundo ante nosotros.

(Valére Novarina, 2008)

\section{La voz en la voz}

Nos proponemos comenzar estas páginas con una pregunta por la voz, una pregunta que se ha vuelto una insistencia en nuestras reflexiones y que específicamente se articula 
con la cuestión de la voz como materia de la lengua ${ }^{1}$. Claramente, esta pregunta no desconoce su complejidad; y se realiza sabiendo que la cuestión ha sido fundamentalmente postulada con anterioridad por Agamben. Los desarrollos de este autor parten de la pregunta por si hay algo así como una voz humana, algo que no sea mero sonido aunque por eso tampoco sea solo significado. Volveremos sobre este punto. Pero antes es importante aclarar que resulta afín a nuestro recorrido la concepción de la lengua de Barthes (1987) como un inmenso tejido sonoro: se trata, precisamente, de la idea del susurro de la lengua, esa experiencia cuyo protagonista es el plano sonoro del lenguaje, aunque no por ello niegue o bloquee el plano semántico de las palabras (más bien, dice Barthes, se lo aleja como un espejismo). De este modo, en esta idea de la lengua, la voz "flota suspendida" (DURÁN, 2014, p. 112), y acaso lo único que pueda afirmarse sea, precisamente, su estado flotante: entre el sonido y el sentido, el significante y el significado, el habla y la escritura. Y cuando hablamos de "materia", quisiéramos hacerlo tomando prestados los términos en los que De Certeau (2008) pensó la voz (en su estudio sobre los dialectos y el impacto sonoro que se experimenta en el mundo de las vocales), voz "que es a la vez, como hálito, su 'materia prima' y, como pronunciación, su degeneración continua por variaciones de sonidos y derivaciones de sentido" (DE CERTEAU, 2008, p. 89). Así, la extrañeza de la materia de la voz radica en ser "materia sonora fluctuante", en exponer un reino donde las voces arman un paisaje de "materia sonora" (DE CERTEAU, 2008, p. 105).

Toda pregunta por la voz, de este modo, nos expondrá a la experiencia de ser algo indeterminado, inconcluso, inasible, incalculable, algo venido de "otra parte", como afirmará Blanchot (2009, p. 13). Y si hablamos de la voz, aunque la pregunta se actualice cada vez y no pueda ser respondida, habrá que decir, con Blanchot (2009), que la voz "todavía no ha dicho nada, que se despierta y que despierta, voz a veces áspera y exigente que viene de lejos y a lo lejos" (BLANCHOT, 2009, p. 41). Pensar la voz, entonces, nos lanza a un vaivén que oscila entre la negatividad y cierta positividad. Decimos Negatividad en un sentido típicamente agambeniano (desde las lecturas de Hegel y Heidegger que el filósofo italiano convoca), donde la voz no puede ser reducida a un mero sonido, pero tampoco puede ser concebida como puro significado, sino que se ubica en ese umbral negativo de ya no / aún no, exponiendo sin resolver el problema de la articulación de la voz (AGAMBEN, 2017). Y decimos Positividad, o más bien, con Foucault (1999, p. 300), "umbral de toda positividad", donde es posible reflexionar tanto la voz en tanto materia, como así también la consideración del límite de la voz cuando la lengua se articula "más allá de sí misma" (HELLER-ROAZEN, 2008, p. 18). En esta línea, donde las inflexiones de una voz dan cuenta de una materialidad (aunque indefinida) y de una localización (pero inaudita), ahí

\footnotetext{
${ }^{1}$ Esta idea es, antes que nada, una sugerencia que hallamos en Agamben (2017, p. 42-43), quien la expone en el marco de una reflexión sobre un comentario a Aristóteles realizado por Amonio; reflexión que discute, por un lado, con ideas de Milner (1980) y, por otro, con la grammatología de Derrida (1971). Ambos movimientos son expuestos en el marco general de un "Experimentum vocis", experiencia que "tiene que aceptar que cada vez se encontrará sin lengua frente a la voz y sin voz frente a la lengua" (AGAMBEN, 2017, p. 47).
} 
pues se abre -tal como lo quería Barthes (2007, p. 66): "en apariencia de verosimilitud e incertidumbre de verdad"- una pluralidad de figuras y ficciones para reflexionar sobre la lengua desde un umbral donde las disciplinas se abren para mostrar las zonas que aún buscan ser pensadas (desde teorías quizá más flexibles, o por qué no, con teorías que asuman su parte de ficción, su parte de poética $)^{2}$.

En este sentido, un texto como Lengua apócrifa de Nancy (2014) nos conduce a la reflexión sobre los sonidos en la especificidad del habla y la lengua en la poesía, poesía que es siempre expuesta como una voz privilegiada en tanto es la encargada de decir que la lengua es apócrifa: esto es, poiesis sin autoridad, sin autenticidad, sin autor; o lo que es semejante, que la poesía no es un metalenguaje ni "un idioma elucubrado", sino la exposición de la materia misma de la lengua: una cosa, una piedra, un objeto, un "bloque o polvo de palabras mineralizadas" (NANCY, 2014, p. 9). Vale decir: los sonidos en la poesía son materia, más allá o más acá de las significaciones. Nancy (2014) expone claramente una cuestión que advirtió Barthes también en su momento: el sentido, el plano semántico, no se anula, no estamos en un terreno de mera insignificancia; sino que se eclipsa (para Nancy) o se vuelve un espejismo (según Barthes). Algo se suspende (eso que llamamos "el sentido") para que la materia de la lengua se exponga en toda su densidad como una “cosa sosteniéndose sola" (NANCY, 2014, p. 9).

En otro texto, titulado "Vox clamans in deserto", Nancy (2007) buscará pensar la voz en la voz. Y lo hará desde un formato singular: un diálogo ficticio e indeterminado donde intervienen las voces de diversos pensadores (Rousseau, Derrida, Sausurre, Kristeva, Agamben, Deleuze, Montaigne) para responder (aunque sin responder de manera directa, sino en reflexiones a veces recursivas, a veces evasivas) a la pregunta "¿qué voz hablará de la voz?". Así, lo que se instala es la pregunta clave por la pertenencia de la voz, es decir: si la voz pertenece solamente al ámbito del habla y de la fonación; o si, por el contrario, acaso pueda decirse que hay voz antes del habla (y en tal caso, la pertenencia sería ¿a qué?). Leemos una de las primeras afirmaciones que se realizan en este texto: "la voz es la cara sonora del habla" (NANCY, 2007, p. 31), pero sin embargo la voz sería solamente una ejecución. La complejidad de esta pregunta por la pertenencia se expone en la hipótesis de la voz como una "precesión íntima extranjera" (NANCY, 2007, p. 32), esto es: pertenece sin pertenecer, no es ni simplemente anterior ni completamente exterior al lenguaje. Con la idea de "precesión", la voz, como cara sonora, queda habilitada a decir en reticencia, en restancia: deja sin decir lo que de alguna manera dice. Toda voz, dirá Nancy (2007, p. 34), "clama en el desierto", es un clamor o una llamada que se deja oír en la extensión, pero su manifestación es del orden de la precesión, y así, en la preponderancia de la cara sonora por sobre la cara significante del habla, se produce no la desaparición sino el eclipse del sentido. Siendo íntima y extranjera, anterior y exterior, la voz para Nancy abre un desierto

\footnotetext{
${ }^{2}$ En este punto, cabe recordar el gesto propio de las operaciones teórico-críticas del trabajo de Michel de Certeau (2008) sobre la lengua, ahí donde este autor pensaba (en el estudio específico de los dialectos en Francia en el S. XVIII, enmarcado en un proyecto de largo alcance) que en el mundo de los sonidos "se juega algo imaginario (...) sobre los bordes y en los intersticios de una lingüística” (DE CERTEAU, 2008, p. 87).
} 
en el pensamiento. Justamente es la voz de Agamben, ficcionada en ese diálogo inexistente que monta Nancy en el texto que comentamos, la que piensa la voz en este caso singular donde la significación no significa (únicamente). $Y$ cabe recordar, entre los tantos textos que Agamben le dedica a este tema de la voz (proyecto que, en "Experimentum linguae" (AGAMBEN, 2004, p. 214) reconoce haber imaginado con el título de "La voz humana") el epílogo del libro El lenguaje y la muerte (2008) titulado "El fin del pensamiento". En esta relación (o mejor, en esta cercanía) que se establece entre la voz, el sonido, el sentido y el pensamiento, Agamben (2008) sostendrá que "el pensamiento es la suspensión de la voz en el lenguaje" (2008, p. 174). Si hay algo que podemos afirmar desde esta teoría es que la voz, al articularse en el lenguaje, se pierde como mero sonido; y es ese umbral (el de la articulación del sonido en letras, o de lo "escribible de la voz") donde se funda "el edificio del saber occidental": una voz eliminada como mero sonido para ser articulada en lenguaje significante (AGAMBEN, 2017, p. 41). Pero sucede que en esa eliminación, hay una experiencia clave: la del pensamiento, la del murmullo del pensar, eso que Agamben (2008) piensa en la escena fónica de un bosque en "El fin del pensamiento", en asociación etimológica de pensamiento y suspensión (pero también, cabe mencionar, en filiación pensante y poetizante con Heidegger). Esto es: en el bosque podemos hacer la experiencia de oír el ruido animal, de esas voces que son pura lengua hundida en el mar semiótico de la naturaleza, ahí donde ningún sonido se articula en sentido y donde, más aún, no hay pensamiento: "La cigarra - es claro - no puede pensar en su chirrido", dice Agamben (2008, p. 174). Entonces, para quienes hablamos, tener una voz es ser conscientes de que justamente - no tenemos una voz, que habitamos el no-lugar de la voz y que el pensamiento será la persecución de esa voz en fuga continua, en búsqueda incesante por "resolver la inexperimentalidad de la voz" (AGAMBEN, 2017, p. 40). Si es cierto que lo que distingue el lenguaje de la voz es su carácter semántico, también es cierto ( $y$ esto Agamben lo problematiza desde Aristóteles) que no hay precisiones sobre qué es lo que vuelve significante la voz animal (AGAMBEN, 2017).

Ahora bien, cabe recordar que toda la reflexión sobre la voz de Agamben está montada sobre una suerte de ficción de origen del habla, o lo que el autor llama "hipótesis" (a la que le reconoce tener para la filosofía una función narrativa). En "Experimentum vocis" (AGAMBEN, 2017, p. 25), este pensador expone su suposición del origen del lenguaje, la cual postula que el "hombre", como todos los animales, siempre habría estado dotado de lenguaje pero que lo que diferenció de los demás fue el haberse vuelto consciente de tener una lengua. Esta conciencia, a su vez, condujo a la separación y exteriorización de la "lengua" en términos de "objeto", y con esto, a su posibilidad no sólo de estudiarlo y analizarlo sino fundamentalmente de transmitirlo. Así, se diagraman dos movimientos: uno de expulsión de la voz (la lengua es expulsada hacia afuera como objeto y así expone a la voz como el no-lugar, su negatividad del ya no mero sonido); y otro, concomitante, de reinscripción de la voz, en el habla y en la escritura - "a través de los fonemas, las letras y las sílabas; y el análisis de la lengua coincidió con la articulación de la voz" (AGAMBEN, 


\section{7, p. 25).}

En esta para-doxa que parece articular continuamente la voz (quiasmos de negatividad y positividad, de expulsión y reinscripción) la hipótesis agambeniana también avanza sobre una cuestión clave: la transmisión del objeto lengua "se divide babélicamente y de a poco va cambiando según los lugares y las épocas" (AGAMBEN, 2017, p. 25). En este punto, Heller-Roazen (2017) es quien, a su turno, continúa esta vía de reflexión de la ramificación o bifurcación de las lenguas; y así, marca un camino para continuar pensando la voz pero ahora ya en las particularidades que la figura específica de Babel adquiere para un buen número de reflexiones contemporáneas. Para el pensador canadiense, una afirmación es clave: "los humanos no se contentan con hablar y con hablar lenguas. También las quiebran y las dispersan, con toda la razón que poseen, en los sonidos y letras de idiomas vueltos múltiples y oscuros" (HELLER-ROAZEN, 2017, p. 18). En ese ejercicio de la facultad del habla, la cual conlleva su misma fractura, la singularidad del "acto de habla" radica en la conciencia de que los hablantes nunca hablan el lenguaje sino que siempre hablan las lenguas, plurales por definición. Así, lo que también expone la pregunta por la voz - expulsada y reinscripta, tan perteneciente al lenguaje como extranjera - es la interrogación por la facultad misma de hablar, y sobre todo, por qué significa hablar una lengua, cuestión que siempre parte, según Heller-Roazen (2017), de la experiencia de la bifurcación de las lenguas, múltiples e innumerables. Vemos así cómo la voz, el habla y la lengua se entrecruzan, menos como nociones o categorías de diversas disciplinas que como figuras que habilitan un modo de pensar, una experiencia de reflexión que busca asumir, como decíamos antes con Barthes (2007), su verosimilitud aparente y su verdad incierta ${ }^{3}$.

En esta línea, pero ahora con Derrida (1985), podría pensarse el habla como una "performance babélica", que pertenece sin pertenecer a una lengua y que ninguna teorización podría dominar completamente. En este marco, la hipótesis posible es aquella que enuncia que la situación babélica supone un saber pre-babélico, en el recuerdo de la lengua única cuyo olvido radica en recordarla (o sea: recordamos que olvidamos hablarla); pero también conlleva un saber post-babélico, el que, desde la escena de la caída de la torre, "todo el mundo sabe qué es una lengua" (DERRIDA, 1985, p. 7). Así, podemos ver a la voz nuevamente en un umbral, pre y post-Babel, situada a la misma distancia del olvido de una lengua única y del saber qué es hablar en la bifurcación de las lenguas.

\section{Voz en Babel}

Preciso es recordar en este momento aquel conocido microrrelato de G. K. Chesterton

\footnotetext{
${ }^{3}$ Hemos trabajado esta cuestión en los términos específicos de "ficción teórica" en el artículo "Imaginar, hacer: ficciones y fricciones teórico-críticas" de Maccioni, Milone y Santucci, publicado en revista Landa, v. 8, n. 1 (2019), al que remitimos. Allí exponemos la apuesta por abrir un uso libre de la potencia común de la ficción para así habilitar la apertura de un método que combine imaginar y hacer. Tal como convocábamos anteriormente y como lo mencionaremos también más adelante, volveremos sobre esta noción en los términos en los que lo realiza Michel de Certeau (1999; 2008).
} 
(apud Blanco, 1995), titulado "La pagoda de Babel", especialmente por las figuras que surgen de Babel: su inconclusión diagrama, por un lado, una torre nunca terminada en la tierra, una suerte de torre sin techo; y, por otro, un pozo sin fondo en el cielo. Esta idea está en el también en Franz Kafka (apud Blanco, 1995), cuando en sus Diarios dice que cavamos la fosa de Babel; y, entre otras menciones, es retomada por Giorgio Agamben en un ensayo de 1966 ("Il pozo di Babele"). La inquietante correspondencia que existe entre la torre inconclusa y el pozo sin fondo, tiene para Agamben (1966) un valor especial para pensar la "obra", la tarea de escribir. Sostiene que:

Después de haber renunciado a edificar la torre que llegue hasta el cielo, los escritores se han puesto a cavar un pozo que llegue al fondo del precipicio del Ser. La época de la torre, del intento de llegar al cielo a través de la obra, ha terminado en la confusión de las lenguas: buscando para la obra un espacio más inmaterial, el escritor cava ahora el pozo de Babel. (AGAMBEN, 1966, p. 46).

Antelo (2014) sostiene que aquí Agamben (1966) estaría retomando un motivo de Martin Heidegger, vale decir, la relación de origen entre el artista y la obra: el artista da origen a la obra pero es la obra (aunque en forma de des-obra e inoperancia) la que da origen al artista. Es el agon entre ergon y parergon, la extrema ambigüedad y ambivalencia que la obra genera respecto de la obra, que como dice Agamben (1966, p. 42): "cuando más cerca se está de expresarla en las palabras, tanto más ella se fuga y no deja más que sus escorias, pero si busca realizarla más allá del parergon, se sustrae precipitándolo a un pozo sin fondo". Vemos que, con la figura del pozo, se convocan problemáticas menos visibles en las teorizaciones sobre Babel, muchas de las cuales casi exclusivamente versan sobre el problema de la confusión idiomática de las lenguas y el consecuente tormento de la traducción.

No obstante la pluralidad de las lenguas y la singularidad de la obra que Babel convoca, algo de las ruinas de esa caída convoca a experimentar esa heterogeneidad como una materia a repensar, a imaginar. ${ }^{4}$ Porque si nos corremos del relato del castigo de la confusión de las lenguas y del problema de la traducción, Babel se nos presenta menos como un relato cerrado sobre la construcción fallida de una torre que como una situación extendida al habla; y esto se da en una escena singular: en el pozo o cavidad donde el sonido pareciera ser agua y donde hablar se asemeja a nadar. Esta vinculación hablarnadar no es antojadiza, sino que la realiza Heller-Roazen (2008) apoyándose en el siguiente aforismo de Kafka:

\footnotetext{
${ }^{4}$ De manera cercana a lo que sostenemos, dicen Larrosa y Skliar (2009, p. 12): "El nombre de Babel atraviesa, por ejemplo, algunos elementos de la tematización contemporánea del lenguaje: si la lengua se pensaba, en el siglo XIX, desde el punto de vista de la representación o, lo que es lo mismo, desde la relación entre significante y significado, hoy tiende a pensarse al modo de la traducción, es decir, desde el punto de vista de la relación y el transporte entre sistemas de signos; frente a los temas clásicos del origen de las lenguas, de su estructura o de sus rasgos comunes hoy nos preocupan sobre todo sus diferencias, sus contaminaciones, sus dinámicas fronterizas, sus aspectos idiomáticos; y cada vez es más claro para nosotros que el sentido mismo no es otra cosa que lo inagotable del significado, lo disperso, confuso o infinito del significado o, dicho de otro modo, el movimiento vertiginoso del intercambio, del transporte y de la pluralidad del significado".
} 
Puedo nadar como los demás, pero tengo mejor memoria que los demás. No he olvidado que una vez no supe nadar. Pero puesto que no lo he olvidado, ahora mi capacidad de nadar no me sirve de nada; entonces, no puedo nadar. (KAFKA apud HELLER-ROAZEN, 2008, p. 147).

La situación del hablante babélico sería, pues, la siguiente: no ha olvidado que una vez habló sin saber que hablaba (la lengua única inhabilitaría la conciencia de qué es una lengua); pero habiendo sido forzado a aprender una lengua particular donde pervive la confusión, aquella capacidad de hablar-sin-saber-que-hablaba es inútil. Situación que tanto Heller-Roazen (2008) cuanto Agamben (1966) vinculan con la afasia: para el estudioso canadiense, la cuestión se da tal como en los afásicos de Freud, de quienes no podría decirse que hablan por los restos o residuos que se evidencian en sus hablas; para el autor italiano, el problema se evidencia en Baudelaire, cuando luego de una visita a la iglesia de Saint-Loup es golpeado por la afasia y solo podrá pronunciar una imprecación. Desde aquí, Agamben (1966) sostiene que la afasia se vislumbra como la vía privilegiada para entrar en la Obra, porque siendo la obra la imposibilidad misma de la obra, la afasia descubre su escondite al ser la imposibilidad de las palabras. Y agrega: "en el vínculo ciego donde se clausura la literatura occidental, la afasia se vuelve un destino; y toda la poesía moderna puede aparecer como un lento camino de acercamiento a la afasia como la mejor de sus salidas" (AGAMBEN, 1966, p. 46). De este modo, la afasia se presentaría, por un lado, no sólo como la imposibilidad de hablar sino también como la inutilidad de saber hablar en seres que no han olvidado que hablaron sin saber que hablaban; y por otro lado, como la vía para zanjar una imposibilidad con otra: la de la obra con la de la lengua misma.

Como sugeríamos, la construcción de la torre conduce no sólo a la confusión de las lenguas y/o al olvido de la lengua única, sino también a la conciencia del habla, a un saber de lo que no se sabía: a un habla que no se olvida de que se supo hablar sin saber que se hablaba. Y en este sentido, Derrida (1985) es quien sostendrá que toda nuestra habla es post-babélica, o sea: que Babel es ya traducción, que de Babel no conservamos más que un nombre, un nombre propio que pertenece sin pertenecer "al borde de la lengua". De Babel no conservamos más que su borde, lo cual nos habla menos de la confusión que de ese saber olvidado y recordado, como el de nadar de Kafka.

Derrida (1985) se detiene en los labios en tanto metonimia del lenguaje: Babel, antes de traducirse por "confusión", quería decir "labios". ${ }^{5}$ Y si Babel es la confusión de labios,

\footnotetext{
5 Así como Derrida (1985), desde Babel y sus desvíos, piensa en los labios como metonimia del habla, Heidegger anteriormente había realizado un movimiento similar a propósito del término "lengua" en De camino al habla. Allí, sostenía que lo que sabemos de la lengua proviene exclusivamente de conocimientos que provienen de la contemplación científica, pero que sin embargo es indudable que algo nos queda del haber hecho una experiencia material de la lengua, con la lengua: esto "lo atestiguan los nombres que las diversas lenguas occidentales se han dado a sí mismas: lengua, langue, language. El habla es la lengua" (HEIDEGGER, 1990, p. 182). Ya sean los labios, ya sea la lengua, lo que parece mantenerse es la dificultad para delimitar un saber sobre la materialidad del habla, un saber que se cifra en una experiencia. Agamben es quien sigue esta línea de indagación cuando en Idea de la prosa piensa esta experiencia como el punto de coincidencia del acabamiento del lenguaje y del advenimiento de "la materia misma de la palabra" (AGAMBEN, 1989, p. 19). En el límite del habla, lo que acontece es la exposición absoluta de la lengua en la lengua, donde el lenguaje se muestra en estado bruto, y donde el poeta (como así también el infante) hace la
} 
también podemos decir que es la multiplicidad de bocas, bocas que en el agua se cierran y en el aire se abren. Como el nadador de Kafka (citado por Heller-Roazen, 2008), la boca que se cierra en el agua no olvida que aprendió a hablar, porque no hablar en el agua no significa negar el habla. En el pozo que es ahora Babel se expone la materialidad de labios musitando sonidos, más acá de un lenguaje, más allá de una lengua.

Pero cabe preguntar: ¿Quién habla de Babel? Es decir: ¿de quién es el relato, desde qué mirada se nos narra ese episodio? Derrida (1985) lo sugiere: el relato de Babel es un relato de Dios y es la perspectiva de ese narrador desde donde se nos cuenta la historia. Con el escritor argentino Perednik (2012, p. 34), agregamos: el capítulo de Babel "se escribió después de Babel”, vale decir, en la lengua de la confusión. Estrictamente, de Babel sólo sabemos su nombre; de la supuesta lengua única sólo avistamos su borde. Y del relato, nos quedamos con la traducción post-babélica de Babel, o sea: "confusión".

"Al hablar siempre hemos comenzado ya a olvidar" (HELLER-ROAZEN, 2008, p. 225), pero si por ello nos hemos transformado en hablantes amnésicos de las ruinas de Babel, lo confuso radicaría más en el uso de la lengua que en la imposibilidad de hablar: el uso de la lengua del cuerpo, la lengua de la boca, la lengua inmersa en la "danza bucal" (DENIS, 1988, p. 86), la lengua que habla más allá de la lengua que se habla 6 . Si es cierto lo que afirma Perednik (2012), esto es, que el episodio de Babel ya es babélico porque está escrito ya en una lengua de la confusión y que por lo tanto sólo podemos leerlo tal como nos lo permite nuestra propia "condición babélica", entonces quizá habría que invertir la figura de la torre en la del pozo, y viceversa. $Y$ así, exponer la situación singular de que hablamos una "lengua impropia" (PEREDNIK, 2012, p. 43), una lengua cuya voz pertenecesin-pertenecer a la lengua, donde la confusión es "el elemento inalterable en toda alteración del habla" (HELLER-ROAZEN, 2008, p. 225). Nuevamente se diagrama un umbral de negatividad/positividad: desde Babel, la voz en el habla da cuenta tanto de confusión cuanto de la "Iabialización" (DENIS, 1988, p. 87) de las lenguas. La materia de la voz se expone en la multiplicidad de labios y se pone a hablar en el "olvido obstinado" (HELLER-ROAZEN, 2008, p. 231) de una supuesta lengua única y en la afirmación flagrante de cada lengua.

Lo inconcluso de la torre se refleja en lo sin fondo del pozo, y así las bocas hablantes ponen "a gozar el sentido en la parte posterior de la garganta" (PONGE, 2000, p. 26), con la boca abierta en lo indeterminado y singular de cada una de las lenguas.

\section{Mundo sonoro}

Si la lengua es un utensilio de aparición, como nos sugiere Novarina (2008) en el epígrafe de estas páginas, lo que aparece es el mundo sonoro en su plena materialidad. Y

experiencia de quien se enfrenta a la inmensidad desnuda del lenguaje, donde éste se expone a la materia de las palabras.

${ }^{6}$ En este punto, es sugerente la referencia al Prefacio de Altazor de Huidobro (1991), donde leemos: "Creé la lengua de la boca que los hombres desviaron de su rol haciéndola aprender a hablar ... a ella, ella, la bella nadadora, desviada para siempre de su rol acústico y puramente acariciador" (HUIDOBRO, 1991, p. 11). Agradezco esta referencia a una lectura anónima. 
en este punto, cabe recordar la indagación sobre elementos extraños que desestabilizan la distinción entre lo sonoro y lo semántico. Por caso, Heller-Roazen estudia las exclamaciones, esos elementos que anuncian una lengua otra en la lengua en la medida en que ubican a la voz en una zona fónica intermedia, entre lo que pertenece a la lengua como sonido y lo que no le pertenece como significado. Dice Heller-Roazen (2008, p. 16): "la lengua traspone las fronteras que normalmente la definen y ahora avanza por una región poco clara de sonidos que pertenecen a la lengua de nadie". Al ser ex-clamación, la voz se extiende en esa región poco clara, ya que estos sonidos no pertenecen a ninguna lengua específica aunque estén en todas las lenguas, en todas las vocales de todas las bocas abiertas. Las exclamaciones son imprescindibles, ya que en la emisión de sonidos extraños la lengua "gesticula más allá de sí misma" (HELLER-ROAZEN, 2008, p. 18), mostrando su intensidad y su extensión sonora.

Acaso en esta misma línea puedan rememorarse aquellas "variaciones ilegibles de la voz" que De Certeau (1999, p. 172) reflexionó cuando pensaba las prácticas escriturarias ahí cuando la voz se comienza a emplazar como "otro"; movimiento que se expone como una "ficción teórica" donde la voz, esa nympha fugax, aparece desplazada en formas de citas. "La voz hace escribir", sostiene De Certeau (1999, p. 174) y son sus rasgos ilegibles los que "rayan los enunciados y atraviesan la casa del lenguaje como elementos extraños, como imaginaciones" (DE CERTEAU, 1999, p. 172). Esos elementos - extraños quizá por resultar extranjeros al lenguaje significativo, en relación a lo que antes mencionábamos como "precesión" en términos de Nancy (2007) - donde la voz convoca a la imaginación y expone su materia fugitiva y alterna, se evidencian como sonidos irreductibles al sentido, ruidos de cuerpos, de cosas, de palabras: "citas sonoras" que espesan la escritura, que hacen de los textos una zona quebrada por una voz sin lenguaje, esto es, una voz que se escabulle de las clasificaciones para mostrarse en su extensión "en el bosque de los signos" (DE CERTEAU, 1999, p. 175) ${ }^{7}$.

En toda su intensidad, en toda su extensión, el mundo sonoro de la voz invita a la reflexión desde diversas perspectivas y, sin dudas, su extrañeza es la que invita a habitar aquellos intersticios o bordes de las teorías más propicios para que surjan las figuras, las ficciones, las imaginaciones que la voz, cada voz, toda voz, e-voca. Es así como en este recorrido hemos podido revisar la figura de Babel, con sus imaginaciones contemporáneas en las inversiones de la torre en el pozo, en el marco general del pensamiento sobre la voz en su relación singular con la actividad de hablar, ahí donde la lengua dice menos de su plano semántico que de la vibración de su materia sonora. Pudimos apreciar, desde Agamben, Barthes, Derrida, de Certeau, Heller-Roazen, Nancy, que la voz no puede sino pensarse -si no se pretende anular su intensidad y su extensión- en los umbrales que se figuran entre el sonido y el sentido. Como materia, como figura, la voz insiste y se insinúa siempre como materia inclasificable. De este modo, las paradojas no nos abandonan

\footnotetext{
7 Hemos trabajado con anterioridad en varias ocasiones la relación entre la voz y la letra en Agamben. Nos permitimos remitir al libro Luz de labio. Ensayos de habla poética (2015).
} 
cuando intentamos pensar la voz: materia fluctuante, sonido liminal, pertenencia reticente. De este modo, en el marco de estas reflexiones contemporáneas, la voz abre un mundo sonoro en cada boca y babeliza la lengua, labializa los sonidos, desestabiliza las teorías para quizá devolverles la parte de ficción que las con-voca.

\section{Referencias}

AGAMBEN, Giorgio. II pozzo di Babele. Tempo presente, n. 11, 1966.

AGAMBEN, Giorgio. Idea de la prosa. Barcelona: Península, 1989.

AGAMBEN, Giorgio. El lenguaje y la muerte. Un seminario sobre el lugar de la negatividad. Valencia: Pre-textos, 2008.

AGAMBEN, Giorgio. ¿Qué es la filosofía? Buenos Aires: Adriana Hidalgo, 2017.

ANTELO, Raúl. El futuro fabuloso, la forma formante y el pozo de Babel. Cuadernos del CILHA, n. 20, p. 95-110, 2014.

BARTHES, Roland. El susurro del lenguaje. México: Paidós, 1987.

BARTHES, Roland. El placer del texto y Lección Inaugural. Madri: Siglo XXI Editores, 2007.

BLANCHOT, Maurice. Una voz venida de otra parte. Madri: Arenas Libros, 2009.

BLANCO, Alberto. El pozo de Lebab (o de la traducción como un trabajo interior). Revista de literatura hispánica, n. 42, 1995.

DENIS, Jean-Pierre. Glossolalie, langue universelle, poésie sonore. Langages, v. 23, n. 91, 1988.

DERRIDA, Jacques. Des Tours de Babel. In: GRAHAM, Joseph F. Difference in Translation. Ithaca and London: Cornell University, 1985, p. 165-207.

DERRIDA, Jacques. De la gramatología. Buenos Aires: Siglo XXI Editores, 1971.

DE CERTEAU, Michel. La invención de lo cotidiano. 1. Artes de hacer. México: Universidad Iberoamericana, Departamento de Historia, 1999.

DE CERTEAU, Michel. Una política de la lengua: la Revolución francesa y los patois: la encuesta Gregorio. México: Universidad Iberoamericana, Departamento de Historia, 2008.

DURÁN, Cristobal. Temblores. Del cuerpo sonoro de Hegel. Buenos Aires: Palonodia - La Cebra, 2014.

FOUCAULT, Michel. Entre filosofía y literatura. Barcelona: Paidós, 1999.

HEIDEGGER, Martin. De camino al habla. Barcelona: Odós, 1990.

HELLER-ROAZEN, Daniel. Ecolalias. Sobre el olvido de las lenguas. Buenos Aires: Katz, 2008. 
HELLER-ROAZEN, Daniel. Langues obscures: I'art des voleurs et des poètes. Paris: Seuil, 2017.

HUIDOBRO, Vicente. Altazor. Santiago de Chile: Editorial Universitaria, 1991.

LARROSA, Jorge; SKLIAR, Carlos (Eds.). Habitantes de Babel: políticas y poéticas de las diferencias. Buenos Aires: Laertes, 2009.

MACCIONI, Franca; MILONE, Gabriela; SANTUCCI, Silvana. Imaginar, hacer: ficciones y fricciones teórico-críticas. Landa, Florianópolis, v. 8, n. 1, 2019.

MILNER, Jean-Claude. El amor por la lengua. México: Nueva Imagen, 1980.

MILONE, Gabriela. Luz de labio. Ensayos de habla poética. Córdoba: Portaculturas, 2015.

NANCY, Jean-Luc. Vox clamans in deserto. In: NANCY, Jean-Luc. El peso de un pensamiento. Pontevedra: Ellago Ediciones, 2007, p. 30-43.

NANCY, Jean-Luc. Lengua apócrifa. Santiago de Chile: Cuadro de Tiza, 2014.

NOVARINA, Valére. Devant la parole. Paris: P.O.L, 2008.

PEREDNIK, Jorge Santiago. El hombre babélico. In: PEREDNIK, Jorge Santiago. Ensayos sobre la traducción. Buenos Aires: Descierto, 2012, p. 33-43.

PONGE, Francis. El silencio de las cosas. México: Universidad Iberoamericana, 2000. Coleção Poesía y Poética.

\section{NOTAS DE AUTORIA}

María Gabriela Milone (gabymilone@gmail.com) es Doctora en Letras por la Universidad Nacional de Córdoba, Argentina. Actualmente se desempeña como docente en la UNC y como Investigadora Adjunta de CONICET. Es Directora Proyecto de Investigación-Consolidar: "Perspectivas materialistas: un abordaje crítico de escrituras contemporáneas" (2018-2022, aval y subsidio de Secyt, UNC) e Investigadora responsable del PICT-Foncyt: "Materialismos Contemporáneos: Perspectivas y abordajes teórico-críticos de la literatura y las artes" (2020-2013, MINCYT).

\section{Como citar esse artigo de acordo com as normas da ABNT}

MILONE, María Gabriela. La materia de la voz: umbrales y figuras. Anuário de Literatura, Florianópolis, v. 26, p. $01-12,2021$.

\section{Contribuição de autoria}

Não se aplica

\section{Financiamento}

Consejo Nacional de Investigaciones Científicas y Técnicas; Universidad Nacional de Córdoba.

\section{Consentimento de uso de imagem}

Não se aplica

\section{Aprovação de comitê de ética em pesquisa}

Não se aplica

\section{Conflito de interesses}

Não se aplica

Licença de uso 
Os/as autores/as cedem à Revista Anuário de Literatura os direitos exclusivos de primeira publicação, com o trabalho simultaneamente licenciado sob a Licença Creative Commons Attribution (CC BY) 4.0 International. Estra licença permite que terceiros remixem, adaptem e criem a partir do trabalho publicado, atribuindo 0 devido crédito de autoria e publicação inicial neste periódico. Os autores têm autorização para assumir contratos adicionais separadamente, para distribuição não exclusiva da versão do trabalho publicada neste periódico (ex.: publicar em repositório institucional, em site pessoal, publicar uma tradução, ou como capítulo de livro), com reconhecimento de autoria e publicação inicial neste periódico.

\section{Publisher}

Universidade Federal de Santa Catarina. Programa de Pós-graduação em Literatura. Publicação no Portal de Periódicos UFSC. As ideias expressadas neste artigo são de responsabilidade de seus/suas autores/as, não representando, necessariamente, a opinião dos/as editores/as ou da universidade.

\section{Histórico}

Recebido em: 10/03/2020

Aprovado em: 19/06/2020

Publicado em: 23/02/2021 